\title{
Reactivity of Carbon Dioxide towards Zirconocene Cations
}

\author{
Michael Hill and Ola F. Wendt* \\ Organic Chemistry, Department of Chemistry, Lund University, P. O. Box 124, S-22100 Lund, \\ Sweden.
}

E-mail: ola.wendt@organic.lu.se

Received XXXX XX, 2005 


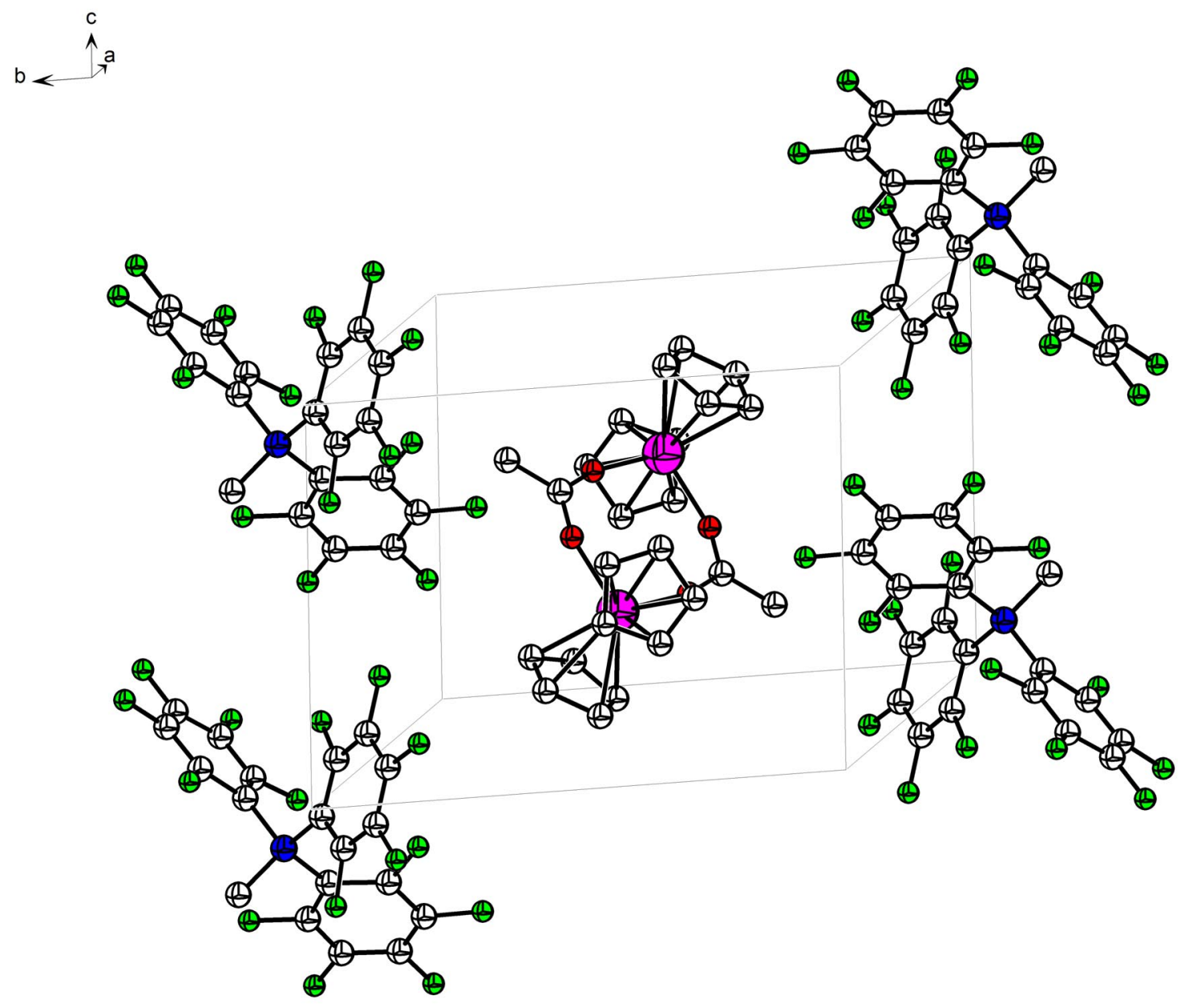

Figure S1. Packing diagram showing the unit cell of $\mathbf{1 2}$. 